\title{
Experiência urbana e narrativas de crime
}

\author{
Paulo Vaz e Gaëlle Rony
}

\section{Resumo}

Neste artigo, propomos que as notícias de crime são, hoje, um elemento decisivo na conformação da experiência da cidade e da alteridade. Para sustentar teórica e empiricamente a proposição, argumentamos, em primeiro lugar, que a retórica dos meios de comunicação usa as lógicas do medo e da compaixão para favorecer a identificação da audiência com 0 sofrimento de estranhos. Na seqüência, analisamos o modo como a descrição da cidade por jovens da elite carioca articula insegurança, pobreza e justiça, reiterando em suas grandes linhas as possibilidades de construção de identidade oferecidas pelas notícias de crime.

\section{Palavras-chave}

Cidade. Crime. Insegurança. Vítima. Identidade. Alteridade.

\section{Paulo Vaz | paulorgvaz@uol.com.br}

Doutor em Comunicação pela Universidade Federal do Rio de Janeiro - UFRJ. Professor do Programa de Pós-Graduação da Escola de Comunicação da UFRJ.

\section{Gaëlle Rony | gaelle.rony@maisondefrance.org.br}

Doutora em Ciências Sociais pela Université Catholique de Louvain. Bolsista recém-doutor da Fundação de Amparo à Pesquisa do Estado do Rio de Janeiro - FAPERJ

Os autores agradecem ao CNPq e à FAPERJ pelo apoio à pesquisa.

\section{Corpo, cidade e insegurança}

Em diversas metrópoles do mundo, o medo do crime afeta o modo como indivíduos experimentam a cidade, pesando tanto sobre escolhas com conseqüências de longo prazo, como a do bairro onde morar, quanto nas decisões cotidianas sobre trajeto para o trabalho e opções de lazer. A eventualidade de ser vítima também é uma questão política maior, com os cidadãos exigindo do Estado que suas rotinas não estejam perpassadas pela possibilidade de serem vítimas de crimes violentos.

Por ser elemento de decisões de indivíduos e objeto de políticas públicas, nos últimos 40 anos, o medo do crime (ou sentimento de insegurança) modificou a aparência das metrópoles ao reforçar diferenças entre bairro de classe média e "periferia", ao estimular a existência de shoppings e de condomínios fechados e ao banalizar as grades por todo lugar.

Talvez pela amplitude, essas mudanças foram descritas e discutidas por diversos cientistas sociais e arquitetos. 0 sentimento de insegurança 
implica, de fato, uma nova articulação entre os corpos e a cidade. 0 objeto de preocupação é o crime cometido por estranhos que ameaça a integridade física e patrimonial dos indivíduos e que ocorre no espaço público, com seleção aleatória de vítimas. 0 crime de proximidade, entre conhecidos, usualmente por razões passionais e que ocorre em espaços privados, como agressões entre cônjuges, não tende a gerar medo e, assim, não afeta a sociabilidade nas metrópoles.

A possibilidade de ser vítima passa a orientar as práticas dos indivíduos nas cidades quando os crimes não são vistos como incidentes, como instâncias isoladas, mas sim como incidências, como mais um caso de um fenômeno - por exemplo, a "violência urbana" - que os antecede e que os sucederá. Através da generalização dos casos, a percepção do crime é uma representação sobre a cidade que associa a possibilidade de ser vítima a características de indivíduos e lugares. Como muitos sabem, embora poucos digam abertamente, no Rio de Janeiro elementos da aparência de estranhos, como raça, etnia e índices de pobreza, são tomados como "marcadores de risco", imprecisos, mas usados na ausência de alternativa.

Para a maior parte dos indivíduos, essa representação sobre a cidade não é formada a partir da experiência direta de ser vítima. Mesmo em cidades com altas taxas de crime, poucos, percentualmente, são vítimas diretas; desse modo, a crença na existência de ameaças à rotina é formada a partir da experiência indireta, isto é, a crença é construída a partir do relato de parentes e amigos sobre suas experiências e a partir do relato sobre sofrimento de estranhos que aparecem nos meios de comunicação. De fato, se para haver medo é preciso que os crimes sejam apreendidos como incidência, os meios de comunicação de massa são uma fonte necessária para os indivíduos se pensarem como vítimas virtuais (VAZ et al., 2005; 2006). Pelo seu modo de funcionamento, por selecionar os acontecimentos que podem interessar a muitos, por articular um acontecimento à vida de cada membro de sua audiência, a mídia necessariamente generaliza os incidentes e cria um nexo entre o sofrimento de estranhos e a rotina de cada indivíduo.

As notícias sobre crime são um dos modos, hoje, de articular os corpos e a cidade. São representações ricas em significados. Implícita ou explicitamente, como na já costumeira representação do "mapa da violência" que por vezes aparece nas páginas e telas dos meios de comunicação, essas notícias descrevem a cidade segundo o critério do risco de vitimização. Mas elas também são uma representação da alteridade, seja pela possibilidade da morte na rotina, seja porque a diferença entre vítima e criminoso está aí disponível para ser articulada a outras separações sociais, como aquelas entre ricos e pobres, morais e imorais e próximos e estranhos. De modo mais direto, nas conversas sobre crime hoje, também se fala sobre cidade, pobreza e moralidade. 
As notícias de crime são, ainda, um discurso sobre a "boa" ordem. Ao narrar um crime, não apenas se descreve 0 incidente; também se expõe como ele poderia não ter ocorrido e por que ele não deveria existir. Quando se fala sobre crime, também se discute concretamente a justiça, a partir da existência de um sofrimento.

Duas questões aparecem imediatamente. A primeira é saber como os meios de comunicação narram os crimes, determinando então os modos de sua retórica participar da constituição do sentimento de insegurança. A segunda é correlata; trata-se de saber como os indivíduos efetivamente apreendem as narrativas midiáticas de crime, construindo seus mapas mentais da cidade pela estimativa das possibilidades de vitimização. De fato, a apreensão das "informações" midiáticas depende das condições sociais de recepção. Como diversos estudos 0 demonstraram, a apreensão do sentido de mensagens não é feita por um indivíduo abstrato; ela depende de gênero, idade, faixa de renda, educação, familiaridade com a mídia, etc.

Essas questões precisam ser elaboradas empiricamente. Na seqüência do artigo, apresentaremos, primeiro, uma síntese de diversas pesquisas empíricas sobre a forma com que o jornal $O$ Globo e o telejornal $R J-T V$ $2^{a}$ edição narram os crimes ocorridos na região metropolitana do Rio de Janeiro nos anos de 2001, 2002 e 2004. A seguir, analisaremos como jovens cariocas, pertencentes à elite social e econômica, pensam as relações entre segurança e hedonismo nas suas experiências da cidade.

\section{A lógica do medo}

As notícias de crime são narrativas sobre 0 sofrimento de estranhos. Pensar seus possíveis efeitos éticos e políticos requer analisar as propostas midiáticas de identificação da audiência com os personagens básicos de uma notícia de crime: a vítima, o criminoso e 0 Estado. Nas culturas ocidentais contemporâneas, uma forma de subjetividade desponta: a vítima virtual. Compreender sua produção é analisar os procedimentos narrativos para articular vítima e audiência. Aqui, duas lógicas de identificação, interligadas, são decisivas: a lógica do medo e a lógica da compaixão.

Em relação à lógica do medo, pode ser dito que praticamente todas as notícias de crime que coletamos de 2001 em diante continham dois fragmentos narrativos. 0 primeiro propõe que 0 crime ocorrido poderia ter atingido qualquer um; o segundo, que esse tipo de crime pode ocorrer novamente. A presença insistente desses dois fragmentos propõe o lugar de vítima virtual à audiência ao afirmar que o crime ocorrido é incidência e que o problema concerne a todos como indivíduos, pois cada um pode ser a próxima vítima.

0 privilégio concedido nas páginas e telas aos crimes cometidos por estranhos e ocorridos no espaço público com seleção aleatória de vítimas é modo de generalizar a eventualidade 
da vitimização. Quando a mídia seleciona como notícia os tiroteios ou assaltos em vias expressas da cidade do Rio de Janeiro (Linha Vermelha, Amarela, Avenida Brasil), o discurso implícito propõe que qualquer um poderia ter passado de carro ou ônibus naquela hora e que foi por sorte que 0 indivíduo não se tornou vítima.

\section{Tomemos o caso da televisão. No RJ-TV $2^{a}$} edição em 2004, foram coletadas 82 notícias que tratavam de crime em 36 dias selecionados aleatoriamente. Pouco menos de 40 notícias narrava um crime; as outras tratavam de ações policiais, eventos no sistema judiciário ou na prisão e de políticas públicas de segurança. Focando apenas nas narrativas de crimes ocorridos, se somarmos assaltos (particularmente latrocínios), tiroteios entre bandidos ou entre policiais e bandidos, crimes como arrastões e balas perdidas e, por fim, demonstração de força dos traficantes, notamos que $68 \%$ das notícias de crime privilegiaram a seleção aleatória de vítimas. Para tornar mais visível essa preferência editorial pela vitimização aleatória, pesquisamos em todas as notícias se elas mencionavam ou não os termos "bala perdida" ou "vítima de tiroteio". 0 resultado surpreendente é que $26 \%$ mencionavam esses termos.

Quando classificamos os crimes segundo seu local de ocorrência, a distribuição claramente indicava que os espaços públicos e semi-públicos da cidade - ruas, praias, universidades, bancos, etc. - são constituídos como lugares perigosos.
E mesmo nas sete notícias de crimes em que 0 local de ocorrência era a residência, três casos referem-se a assaltos, um à "ordem de despejo" de uma moradora de favela promulgada por traficantes e outro a uma chacina que a polícia afirmou ser de responsabilidade do tráfico. 0 telejornal constitui a cidade por inteiro como arriscada; não surpreende, pois, que o pai de uma vítima de tiroteio ocorrido num assalto a banco em novembro de 2004 diga: "é complicado você sair hoje de casa; até em casa você corre risco".

Uma última classificação aplicada às ocorrências criminais noticiadas no RJ-TV $2^{a}$ edição distinguia as formas possíveis de relação entre criminoso e vítima. Se 0 atributo de existência de um fenômeno for sua veiculação pela mídia, não houve crimes tipicamente passionais no Rio de Janeiro em 2004, pois não houve nenhum caso onde 0 agressor era conhecido e tinha relação de familiaridade com a vítima. Ao mesmo tempo, $75 \%$ dos crimes teriam sido cometidos por pessoas absolutamente estranhas.

0 privilégio nítido dado aos crimes cometidos por estranhos no espaço público com seleção aleatória de vítimas é modo de incitar a identificação da audiência com a vítima sob a lógica do medo. Embora esse privilégio seja forma de propor que esses tipos de crime podem acontecer com qualquer um, as notícias insistem em mostrar que eles podem acontecer novamente. No noticiário televisivo, a estratégia retórica mais utilizada é colocar uma vítima, 
direta ou virtual, comentando o sentido desse evento para a vida na cidade e, portanto, transformando o incidente em incidência. Eis algumas frases ditas ao longo do ano de 2004: "Não vou viver aqui de jeito nenhum" (moradora após um tiroteio na Linha Amarela); "Com essa insegurança, com essa instabilidade, com essa sensação de impotência, a gente não pode continuar vivendo numa cidade como essa" (moradora da Lagoa após um assalto a edifício); "Pessoas estão aterrorizando a cidade e o bairro, e a gente ainda tem que compactuar com isso daqui" (pai de aluna que teve aula interrompida pela disputa de ponto de venda de drogas na Rocinha); "Não agüento mais de medo; não consigo mais sair de casa" (moradora de Santa Teresa, durante um protesto); "É um terror, nós vivemos em desespero constante e sempre com aquele pensamento de que vai haver alguma coisa, né?" (moradora comentando sua experiência de morar perto da casa de detenção de Benfica). E quem já não leu ou ouviu a "inevitável" pergunta sobre se a vítima vai continuar a morar na cidade?

Colocar indivíduos comuns para falar do medo que afeta a muitos não é a única estratégia retórica de identificação da audiência com a vítima. 0 discurso dos "âncoras" ou dos repórteres também costuma repetir que o incidente é uma incidência: "Em menos de um mês, outros dois moradores morreram por balas perdidas"; "Essa foi mais uma madrugada de medo para a comunidade"; "Mais um confronto entre policiais e bandidos; mais duas vítimas"; "E desde a noite da última quarta-feira 16 pessoas foram mortas em confronto com a polícia"; "Mais um caso de seqüestro-relâmpago no Rio"; "Em seis meses, pelo menos 23 pessoas já morreram", etc.

Uma terceira estratégia discursiva, mais radical, de identificação entre vítima e audiência sob a lógica do medo aparece em notícias sugerindo que até a polícia está intimidada pela "violência urbana". Após relatar a morte de um motorista baleado durante 0 assalto ao seu carro, 0 repórter mostra que a delegacia próxima se trancou com cadeado. A justificativa do delegado é significativa: a delegacia estava rodeada por 14 favelas.

Nessa última notícia, está implícita a relevância do segundo aspecto na constituição do medo: a imagem do criminoso (e dos lugares onde é dito que mora). Por seu uso político nos Estados Unidos após o atentado de 11 de setembro, é possível perceber que o medo será tanto maior quanto mais os criminosos forem descritos pelos adjetivos "organizados" e "conspiradores". Quanto mais se repetia que a Al-Qaeda era uma organização descentralizada, com células espalhadas pelo mundo, prontas para agirem autonomamente, sempre capazes de renascerem se por acaso alguma fosse destruída, mais fácil era sustentar a possibilidade de um novo ataque. Do mesmo modo, a tendência da cobertura midiática dos crimes no Rio de Janeiro é, em primeiro lugar, atribuir muitos crimes aos traficantes, mesmo aqueles onde a informação 
disponível ao repórter é escassa. Em segundo lugar, os traficantes tendem a ser descritos como mais organizados do que são - ao menos se for aceita a descrição de cientistas sociais brasileiros como Misse (2006) e Zaluar (1998) - e com penetração cada vez maior na sociedade; é comum os jornais e a televisão destacarem que cantores, jogadores de futebol e celebridades conhecem algum traficante poderoso. A identificação da audiência com a vítima sob a lógica do medo forma aqui uma separação entre "nós" e "eles": cada membro da audiência é convidado a se conceber como ameaçado por um grupo de indivíduos estranhos e organizados.

A variação do medo segundo a imagem do criminoso depende também da possibilidade ou não de compreender suas ações. Parte do temor dos terroristas dependia de serem descritos ora como dispostos a tudo, ora como fanáticos, com crenças exóticas, absolutamente convencidos não só da existência de vida após a morte, mas de que haveria recompensas espetaculares no além para seus sacrifícios. Na cobertura do crime, essa incompreensão é realçada seja através da maldade monumental dos "chefões", seja através do singular desprezo pela vida alheia comum a todos os bandidos. Nos anos de 2001 e 2002, o jornal $O$ Globo, quando narrava um assalto à mão armada, colocava a vítima a dizer que não reagiu diante da arma apontada, sugerindo implicitamente que reagir seria arriscado quando se lida com "bandidos" sem consideração pela vida. Para confirmar a imagem, nos assaltos em que a vítima foi baleada, o jornal frisava que ela ou reagiu, ou tentou fugir. Talvez o caso mais revelador dessa construção de imagem tenha sido um assalto onde houve a quebra do quase-contrato entre indivíduo e bandido: uma senhora, mesmo não tendo reagido e entregado o dinheiro, foi baleada na cabeça. Ao lado da notícia, o jornal coloca num box um policial afirmando seu espanto diante de tanto desprezo pela vida (sobre esses casos, ver VAZ et al., 2006).

Essa imagem do criminoso afeta, por derivação, as favelas, o lugar onde esses criminosos são ditos morar ou se refugiar - e, por aproximação, todos os moradores que podem parecer criminosos, notadamente jovens do sexo masculino. Ao longo do ano de 2004, por diversas vezes alguma favela apareceu visualmente no telejornal. Uma imagem típica era a de policiais sobrevoando de helicóptero a comunidade, com fuzis apontados para baixo. Ou policiais entrando a pé, com armas empunhadas, prestes a atirar. E os comentários de jornalistas ou indivíduos apenas reforçam a associação entre favela e risco. Além da já mencionada "justificativa" do delegado para colocar correntes na delegacia, a cidadã que morava perto da antiga Casa de Custódia de Benfica, ao comentar a resolução do governo estadual de torná-la centro de triagem para prisioneiros que estavam no fim de suas penas, afirma: "Vão misturar outra vez facções diferentes, num bairro que tem várias favelas; vai ser muito pior". 
Essa associação entre favela e risco tem efeitos, como veremos mais à frente, quando analisarmos a fala de jovens da elite carioca sobre 0 crime. Mas um desses efeitos, a naturalidade com que se aceita a intervenção policial violenta nas favelas, já está presente no discurso midiático. No início de 2004, um tiroteio entre traficantes e policiais perto da Linha Amarela provocou a morte de um pastor e sua mulher por bala perdida quando passavam de carro. No final, o repórter anuncia as medidas tomadas pela autoridade policial após o evento: em primeiro lugar, "para evitar que motoristas sejam atingidos em caso de tiroteio, as equipes da polícia não vão ficar mais baseadas perto da via expressa"; em segundo lugar, "vão aumentar o número de policiais de 100 para 240 que ocupam o Complexo da Maré". Deve ser surpreendente para um estrangeiro saber que um modo de proteger os indivíduos na cidade do Rio de Janeiro é afastá-los da proximidade da polícia; também deve ser surpreendente que o noticiário não questione se 0 aumento do efetivo policial acarretaria ou não mais confrontos e, portanto, mais riscos de bala perdida para quem mora no Complexo da Maré.

\section{Compaixão e indignação}

Assim como o medo, a compaixão também tem sua lógica. Embora seja comum a crença de que as emoções são naturais, tendo forma e sentido independente da cultura, para quem investiga se os meios de comunicação são capazes de produzir subjetividade e comunidade, é interessante tomar como ponto de partida a possibilidade de as emoções implicarem crenças que as definem. No caso da compaixão como sentimento doloroso endereçado ao sofrimento de outro indivíduo ou ser vivo, três crenças são reconhecidas desde Aristóteles como decisivas para sua existência (NUSSBAUM, 2001).

A primeira condição é um juízo de gravidade sobre o sofrimento. Se porventura o observador acreditar que 0 sofrimento do outro foi ocasionado por algo insignificante, ele recusa a compaixão; inversamente, é possível que um observador sinta compaixão por alguém que não saiba que está sofrendo, como é o caso na atitude perante a "alienação" de modo geral, seja em relação à loucura, seja na crítica midiática ao entretenimento.

Fica claro, portanto, que a compaixão é uma emoção de observador, pois é ele quem decide sobre a gravidade do sofrimento do outro. E como emoção de observador, a compaixão tem laços estreitos com a vergonha e a culpa. São emoções sociais e socializantes. Vergonha e culpa paralisam a ação ao desdobrarem um indivíduo entre o que ele deseja fazer e 0 que deve ser; 0 dever, por sua vez, mantém relações mais ou menos diretas com o sofrimento que a ação desejada supostamente causa no outro. Vergonha e culpa, portanto, limitam as ações que supostamente causam danos a outros; a compaixão completa 0 elo de sociabilidade ao estimular a solidariedade, ao incitar os 
indivíduos a agirem para reduzir o sofrimento de terceiros.

0 segundo juízo necessário para a existência da compaixão define a inocência do sofredor. A solidariedade existe se 0 observador pensar que 0 sofrimento não foi merecido, que sua existência se deveu à má sorte. A compaixão é orientada pela moralidade, na medida em que será negada a compaixão para aqueles que, por seu comportamento imoral, são tidos como responsáveis pelo seu sofrimento, como na distinção entre "vagabundo" e "desempregado" que orientou a ajuda aos pobres durante parte do século XIX. Mais radicalmente, a moralidade orienta a compaixão por que institui duas crenças correlacionadas: que a moralidade é forma de prevenir sofrimentos e que a contingência é negativa, é o que deve ser paulatinamente eliminado. De modo mais simples, é comum se pensar que o sofredor, se for tido como imoral, teve o que "merecia", o que significa, sob outro ponto de vista, que o comportamento moral seria capaz de impedir sofrimentos e que nas ocasiões onde não foi capaz, ocasiões em que o observador sente compaixão, isso se deveu à ação negativa da contingência.
Há, porém, uma possibilidade de sentir compaixão pelo sofredor, mesmo quando se pensa que suas ações imorais provocaram seu sofrimento. 0 observador mantém a validade da regra moral, mas recusa sua aplicação para 0 caso. A recusa depende de uma construção específica do comportamento do sofredor. Ao invés de agir livremente, suas ações imorais foram determinadas: por uma parte dele mesmo, pelas circunstâncias, pela educação recebida, etc. Generalizando, as ações imorais estavam além de seu controle, como se ele fosse um "doente mental", um "anormal": mais do que ser condenado, precisa ser curado. Mas tanto nas ocasiões onde só sente compaixão pelos morais, quanto naquelas em que recusa a aplicação da regra moral para o caso, o observador mantém seu olhar inocente ao se identificar com a vítima, mantém seu vínculo com as regras morais da sociedade em que vive ${ }^{1}$.

0 terceiro juízo necessário à existência da compaixão é o de possibilidades similares. É preciso se colocar no lugar do sofredor e imaginar como seria experimentar aquele sofrimento.

Embora esteja à distância por ser um observador, quem experimenta compaixão também

Há uma segunda possibilidade de estender a compaixão para o "imoral” - é recusar a própria regra moral, e não simplesmente sua aplicação para o caso. Não se pode, porém, classificar imediatamente essa emoção como compaixão. Em primeiro lugar, por que 0 "imoral" deixa de ser vítima e torna-se senão alternativa de vida, ao menos ponto de inquietação sobre 0 sentido da vida para 0 observador. Em segundo lugar, por requerer a crítica da moralidade pelo observador, aquele que a experimenta está em luta contra a vergonha e a culpa. Em terceiro lugar, essa atitude talvez recuse a construção da contingência como adversário a ser eliminado. Certamente essa forma de extensão da "compaixão" foi proposta por Foucault em sua crítica do dispositivo de normalização; mas também orientava sociólogos pertencentes à teoria do rótulo nas suas análises da criação do desviante, como Goffman e Gusfield. Por fim, também fica clara a raridade histórica dessa extensão da compaixão; para ela existir, é preciso que parte significativa da sociedade não esteja apenas questionando a forma social de distribuição de riquezas, mas também as regras morais sob as quais cada um experimenta a si mesmo e ao outro. 
experimenta medo. E sua intensidade depende de 0 quanto 0 observador pensa estar à distância daquele sofrimento. Como argumentamos anteriormente, no caso dos crimes ocorridos no espaço público e com seleção aleatória de vítimas, essa distância se reduz brutalmente.

Pelo juízo de possibilidades similares, percebe-se como os processos discursivos de identificação entre vítima e audiência mesclam as lógicas do medo e da compaixão. Mas a compaixão está também misturada com a indignação. Existe uma tradição filosófica, que começa com os Estóicos e chega a Nietzsche, que é crítica da compaixão exatamente pelos seus laços com a ira e 0 ressentimento. A compaixão observa 0 sofrimento a partir de uma compreensão da responsabilidade. Essa compreensão tanto determina a inocência do sofredor, quanto busca os responsáveis se o que sofre é tido como vítima. Em outras palavras, a compaixão requer a crença de que a imoralidade causa sofrimento; se 0 sofredor for tido como inocente, se ele não teve o que merecia, a tendência do observador será buscar a causa do sofrimento na imoralidade de terceiros. A compaixão requer a crença na idéia de sofrimento evitável.

Por seguir a lógica da compaixão, o noticiário de crime é fonte de crenças sobre a responsabilidade pela existência de crimes. Semelhante a outras narrativas sobre o sofrimento de estranhos, como notícias sobre catástrofes naturais ou acidentes de carro e avião, o discurso midiático não insiste apenas sobre 0 horror do experimentado pelas vítimas inocentes e como essa experiência poderia ter sido a de muitos; 0 discurso insiste também em descobrir as causas para a ocorrência do evento e, assim, como ele poderia ter sido evitado ou seus efeitos danosos reduzidos.

Para pensar que um furacão poderia não ter provocado tantas vítimas, a atribuição de responsabilidade não pode se deter apenas no agente natural; é preciso supor que seres humanos teriam poder para prevenir ou agir a tempo para reduzir os sofrimentos. No caso do crime, também a responsabilidade causal pelo sofrimento não é lançada apenas sobre os criminosos. Desde a década de 1980, quando se deixou de acreditar em revolução e engenharia social, torna-se cada vez mais desacreditada a causalidade estrutural para os sofrimentos humanos. Desse modo, se um crime ocorre, a responsabilidade será atribuída a falhas das agências estatais de controle social: o judiciário, a prisão e a polícia. Sob esse ponto de vista, cada reportagem é tanto um drama moral, quanto forma de apontar uma crise de legitimidade do Estado, ao se denunciar suas falhas que teriam permitido a existência do sofrimento, aprofundando a distância entre os "políticos" e os cidadãos. Para algumas notícias de crime, de fato, é difícil determinar se seu objetivo maior era suscitar a compaixão pela vítima, ou apontar a imoralidade (na forma da "maldade") dos criminosos, ou alimentar a indignação em relação ao Estado. De todo modo, uma vez mais, 
os incidentes tornam-se incidências; todo crime

- hoje, praticamente todo tipo de sofrimento

- pode ser exemplo da incompetência, descaso

e corrupção daqueles que deveriam zelar por

nossa segurança.

Para apreender essa forma historicamente singular de construir a idéia de sofrimento evitável, uma estratégia é analisar se as notícias de crime apontam falhas do Estado e quais falhas são privilegiadas. Retomemos o noticiário do RJ-TV em 2004. Considerando toda e qualquer notícia de crime, independentemente de seu foco principal - crime, ação policial, evento no judiciário ou prisão, etc. - do total de 82 matérias, 52 (63\%) continham algum tipo de crítica. Em termos de freqüência diária, em apenas três dos 36 dias sorteados não houve reportagem que incluísse alguma denúncia sobre a atuação falha de um desses dispositivos estatais de segurança.

Em relação ao judiciário, as críticas privilegiaram a concessão de habeas corpus a suspeitos e a oposição dos juízes à proposta da polícia de distribuir listas com os nomes de "baderneiros" contumazes às boates. Em relação à prisão, os temas dominantes foram a frequiência de motins, rebeliões e fugas, a corrupção dos agentes penitenciários e a ocorrência de homicídios no espaço público que teriam sido ordenados de dentro da própria prisão. No que diz respeito à polícia, as críticas expõem uma polícia que não soluciona crimes, que nunca está onde deveria estar e que quase sempre chega tarde demais (e quando chega a tempo, ou os bandidos conseguem escapar, ou sua atuação expõe a população a riscos ainda maiores). Igualmente comum é a referência de que o reforço de contingente em determinadas áreas só acontece após a notícia de crimes pela imprensa e que os bandidos, de modo geral, não se intimidam com a proximidade da polícia.

Em 71\% das críticas à atuação do Estado em relação à segurança, vê-se claramente a retórica característica do populismo penal, tipicamente conservador, a saber: se as leis fossem mais rigorosas, se a prisão contivesse os criminosos, e se houvesse mais polícia para intimidar os bandidos, não haveria tantos crimes na cidade do Rio de Janeiro. Uma porção significativa das demais críticas à atuação da polícia (cerca de 20\%) refere-se aos excessos cometidos por policiais durante suas ações nas favelas. Parte da audiência pode interpretar as notícias como denúncias de violação dos direitos dos moradores; outros, contudo, podem avaliar os excessos como danos colaterais inevitáveis na "guerra" contra o tráfico. 0 caso típico é o de moradores de favela inocentes mortos por "balas perdidas" durante incursão policial. É notável, ainda, que apenas em menos de 10\% do total de críticas à ação do Estado, houve referência a má conduta ou abuso de poder por parte de policiais.

No cômputo geral, para 0 ano de 2004, foi de cerca de $80 \%$ a probabilidade de que um indivíduo, assistindo ao RJ-TV, se defrontasse 
com reportagens em que o poder dos criminosos aliava-se à ineficiência do Estado em prover segurança às pessoas. Pela reiteração cotidiana, pode-se supor que grande parte da audiência tenda a acolher esse diagnóstico, que correlaciona o poderio dos criminosos à ineficiência do Estado como sendo uma explicação razoável do quadro atual da segurança pública. Sobretudo porque as críticas não aparecem na forma de editoriais, mas por meio de comentários curtos, expressões corporais dos jornalistas ou frases selecionadas do "público em geral". Eis mais alguns casos: "Mesmo após confessar, a Justiça concedeu habeas-corpus"; "No dia seguinte ao assassinato do comerciante pelos bandidos, o carro-patrulha da polícia desapareceu (da esquina perto do assalto)"; "É impressionante a reincidência de coisas (assaltos), e ninguém faz absolutamente nada".

\section{A elite fala da cidade e do crime}

Após a análise de como a mídia constrói a realidade do crime usando as lógicas do medo e da compaixão, cabe investigar como se dá a apropriação dessa construção. Para tanto, foram realizadas 15 entrevistas semi-estruturadas, cada uma com cerca de 1 hora de duração, com jovens que cursavam Direito ou Economia na PUC-Rio, todos de família de classe média alta, moradores da Zona Sul e que tinham feito o segundo grau em colégios tidos como dos melhores da cidade; em suma, todos os entrevistados podem ser tidos como membros da elite econômica e social. Anteriormente, argumentamos que as conversas sobre 0 crime eram também modos de falar da cidade, da alteridade e do Estado. Durante as entrevistas, ficou clara a imbricação entre experiência da cidade, ordem moral, escolhas de políticas de segurança e modo de se atribuir uma identidade.

A entrevista foi conduzida por um dos autores; como se trata de uma francesa que pode ser considerada da mesma faixa etária dos entrevistados, os jovens da elite procuravam ao longo da entrevista argumentar como a cidade do Rio era interessante e bela. Como todos já tinham viajado ao exterior, como tinham olhado para a "realidade brasileira" sob a perspectiva da diferença, os jovens colocavam-se no lugar da entrevistadora e se esforçavam também para justificar aquilo que a seus olhos seria "chocante", especialmente a desigualdade social. Embora não fossem consumidores ávidos de notícias, cabe dizer ainda que assistiam ocasionalmente a telejornais noturnos ou liam jornais diários; ao longo do dia, passeavam pela Globo News ou entravam em sites de notícias e liam de modo intermitente alguma revista semanal, principalmente a Veja - esses jovens eram bastante homogêneos no que se refere ao acesso a fontes de informação.

A primeira pergunta da entrevista pedia para os jovens descreverem o bairro onde moravam. Sistematicamente, essa pergunta sobre a vida cotidiana e a cidade conduzia os entrevistados a 
falar sobre insegurança e pobreza. Uma expressão onipresente resume esse nexo: "Eu tenho vista pro mar e pra favela. Você tem a favela e 0 bairro mais nobre da cidade (B)"². Essa coincidência não se deve apenas ao fato de que 0 Rio de Janeiro é uma cidade efetivamente perigosa; como indicam diversos estudos, a possibilidade de ser vítima é elemento de descrição mesmo em cidades com taxas de crime bem menores que as do Rio.

0 sentimento de insegurança está "situado"; 0 medo depende da significação que os indivíduos dão ao espaço habitado (PAIN, 2000). Desse modo, as questões do crime e da pobreza são cada vez mais pensadas através de categorias espaciais, como o mostra a recorrência das oposições entre cidade e periferia (ou favela e asfalto) no Brasil e em outros países.

Um primeiro lugar para se perceber a relevância das notícias de crime é o modo como os entrevistados descrevem a diferença entre 0 bairro em que moram e o resto da cidade. Como se sabe, só é notícia o excepcional; inversamente, para a maior parte das pessoas, na maior parte do tempo, nada acontece em suas rotinas. Essa diferença é espacializada; os lugares da cidade que fazem parte da rotina dos indivíduos são conhecidos e raramente algo acontece neles, mesmo que a taxa de crimes seja elevada. Os lugares que se desconhece ou pelos quais pouco se passa, ao contrário, só são objetos de experiência mediada: só se sabe deles o que foi noticiado. A relevância dessa diferença entre rotina e experiência mediada aparece com clareza no comportamento de quem pouco sai de casa, como idosos ou turistas; para estes, a cada lugar, o que aconteceu a estranhos na mídia pode acontecer com eles: um arrastão na praia, um assalto em ônibus, um tiroteio em alguma linha expressa, etc.

A diferença entre lugares pertencentes ao rotineiro e aqueles que se conhece através da mídia existe mesmo para aqueles que moram em bairros tidos como violentos: uma moradora de uma favela do Rio de Janeiro temia passar pelo Largo do Machado, uma praça da Zona Sul (CAVALCANTI, 2007). Para os jovens entrevistados, essa diferença entre rotina e experiência mediada aparece quando descrevem seu bairro, sempre apresentado como tranqüilo, enquanto o resto da cidade é descrito como caótico, desorganizado, perigoso.

De modo genérico, os jovens entrevistados descrevem suas rotinas como caracterizadas pela proximidade com a natureza (a praia, a Lagoa), pelo acesso à cultura e pelas oportunidades de prazer; em suma, a rotina como lugar de valor é definida por um hedonismo difuso. Reivindicam, assim, a pertinência à "Cidade maravilhosa", identificando-se como cariocas e moradores da Zona Sul - vários sublinharam que seus pais e avós já moravam em Ipanema ou Lagoa. Embora 
reconheçam que a possibilidade de ser vítima é elemento do modo como calculam suas rotinas, vários insistiram que, apesar do risco, não mudam seus hábitos; a frase emblemática é "Eu não deixo de fazer o que gosto (D)". A rotina prazerosa é o que está ameaçado pelo crime e é também 0 justo, o que se deve lutar para existir, mesmo que individualmente: "Eu posso ser assaltado, né. Isso dá medo, dá medo! Agora viver com medo, eu não vivo. Isso não me aprisiona (B)".

Essa posição de justiça pode ser generalizada, reconhecida como direito de todos. A sociedade deveria estar ordenada de modo a permitir que todos tivessem oportunidades de ter prazer. Essa posição moral implica uma forma de humanismo onde a violência é condenada por princípio (MICHAUD, 2002) e a sorte daqueles que não têm tantas oportunidades e ainda sofrem com o crime pode ser lamentada.

Esse discurso de tom humanista tem um limite que aparece claramente quando os entrevistados discutem as causas e soluções para a "violência urbana". A partir desse humanismo, a segregação social e a falta de oportunidades são designadas como causas do crime; contudo, quando apontam soluções, vários entrevistados privilegiaram as políticas de "pulso firme" - mais polícia, leis mais rigorosas, etc. - sobre políticas de redução das desigualdades sociais. Por que essa disjunção entre a causa designada e a solução? Se os entrevistados acreditam que os crimes ocorrem pelo fato de os jovens pobres terem poucas oportunidades legítimas de ascensão social, por que os entrevistados não defendem políticas de redução de desigualdades?

Essa disjunção é, de fato, o lugar onde 0 sentimento de insegurança afeta o sentimento moderno básico de justiça, que é a igualdade. De um lado, os jovens admitem que a segregação social causa o crime, ao reconhecerem que a desigualdade pode limitar as oportunidades; nessa posição, os pobres, aí incluído os criminosos, são construídos como vítimas. De outro lado, pelo sentimento de insegurança e pela causalidade atribuída à segregação social, esses jovens da elite se concebem como vítimas dos criminosos pobres, se concebem como injustiçados porque são impedidos de extraírem de suas rotinas todo prazer a que teriam direito. Ao mesmo tempo, pelo descrédito recente das crenças e práticas de engenharia social (crise do Estado de Bem-Estar e da revolução) e pela crise da política, no "mercado de idéias", há poucas crenças disponíveis para que esses jovens se vejam como responsáveis pela existência do crime por serem capazes de mudar a sociedade, reduzindo as desigualdades sociais e, assim, supostamente, o número de criminosos e a incidência de crimes. 0 outro lado da descrença na transformação do homem e da sociedade é a presença insistente da crença nas falhas do Estado; como vimos, o discurso midiático reitera que a existência de crimes se deve à incompetência e corrupção dos agentes estatais de controle social. 
Vedada a alternativa de se conceber ao mesmo tempo como vítima e responsável, restarão possibilidades restritas de articular a injustiça relativa à rotina ameaçada com a injustiça relativa à desigualdade das condições sociais. Elisa Reis, em suas pesquisas sobre a visão da elite brasileira sobre a pobreza, descreve uma resposta possível: a pobreza não é tanto um problema para o pobre e, sim, para o não-pobre (REIS, 2005). Em outras palavras, a pobreza é problema porque 0 crime reduz a qualidade da vida urbana, porque é ameaça à propriedade e à integridade física dos não-pobres. 0 ponto de fixação do juízo de valor não é a desigualdade entre os homens, mas o fato de ela ser excessiva, sendo o excesso o que teria papel causal na existência de crimes. Ou ainda, o lugar de valor a partir do qual se pensa a justiça social é a rotina ameaçada. Nessa perspectiva, a associação entre crime e desigualdade torna a pobreza um objeto de políticas de redução do risco e um marcador de aparência a ser usado na experiência com o outro.

A grande maioria dos entrevistados citou a educação como resposta de longo prazo para 0 problema do crime. Como disse um jovem, "0 que mais me desagrada no Rio é a questão da pobreza, no sentido de que você não está entre iguais, não tem oportunidades iguais (B)." No contexto da entrevista, porém, essa proposição coloca a educação como modo de desviar os jovens pobres de seu destino quase inevitável de se tornarem traficantes ou bandidos. Essa juventude é, assim, definida como um conjunto de criminosos em potência, como um risco para 0 grupo com o qual os entrevistados se identificam. Uma segunda perspectiva mantém o privilégio da vítima de crime como lugar de se pensar a boa ordem (e, portanto, mantém o lugar dos jovens entrevistados como vítimas), mas articula essa posição com a desigualdade social, agora não como o que explica a existência de crimes, mas como o que pode tornar um grupo mais vítima do que outro. Os pobres seriam as vítimas maiores da violência urbana tanto porque são os que mais sofrem diretamente com a ação dos criminosos, quanto porque a associação entre pobreza e risco faz com que sejam vítimas de preconceito de todos e, em especial, da ação dos agentes estatais de controle social: não se preocupam em policiar os locais onde moram; se a polícia está nas favelas, trata a todos como criminosos; 0 judiciário condena indivíduos nem tanto pelo que fizeram, mas pelo que são (ZALUAR, 1998), etc.

A diferença entre as duas perspectivas se dá na extensão do "nós" das vítimas de crime. A variação entre os jovens a respeito da extensão da comunidade das vítimas não dependeu tão somente de diferenças individuais, até pelo fato de que em todas as entrevistas a extensão era diferentemente definida de acordo com o que estava sendo discutido. De acordo com as proposições teóricas sobre a lógica da compaixão, em especial o juízo de possibilidades similares, parece-nos que a variação dependia da intensidade do sentimento de insegurança 
suscitada por um dado crime. Se os jovens conseguiam se colocar à distância da vítima, mais fácil era haver outros elementos de justiça na sua apreensão do "outro" além da rotina ameaçada; se a proximidade com a vítima era maior, a posição de vítima virtual preponderava na descrição das soluções possíveis para a questão da "violência urbana".

Os argumentos de Machado da Silva sobre a "geometria variável" da justiça na sociedade brasileira apresentam um caminho para se pensar a variação na extensão do "nós" (SILVA, 2004). A vida nas grandes cidades brasileiras seria organizada pelo princípio do recurso à força, sem que se abandone a referência à ordem institucional e legal. De fato, essa referência é mantida, mas sempre podendo ser transgredida em certos contextos - isto é, sob certas condições, como na frase "estamos em guerra", 0 uso da violência do Estado é necessário. Para simplificar, denominaremos essas duas ordens morais em convivência de "Lei" e "Força".

A ordem moral da Lei é marcada pelo humanismo, com referências às normas dos direitos humanos e do direito à vida. Nessa ordem, a comunidade das vítimas é inclusiva, compreende todos os que são vítimas da violência, com alguns jovens até expressando a crença de que os "pobres inocentes" são as maiores vítimas. A ordem da Força, por sua vez, é aquela onde 0 uso da violência, privada ou estatal, tem 0 estatuto de necessidade. Nesse caso, a comunidade imaginada de vítimas pode se reduzir ao grupo social das classes favorecidas.

\section{Essa interação curiosa entre a Lei e a Força} pode ser reveladora. Nossa hipótese é a de que 0 discurso sobre 0 crime contém inevitavelmente um problema na identificação da vítima que está associado à co-existência das duas ordens morais e do lugar dos pobres ora como riscos para a elite, ora como também vítimas. A dificuldade cognitiva reside na determinação da fronteira simbólica do seu grupo.

\section{0 registro inclusivo}

No registro inclusivo, no grupo alargado, as fronteiras da segregação social não determinam totalmente a separação entre vítimas e criminosos. Ao mesmo tempo em que se consideram vítimas virtuais, os entrevistados escolhem entre os outros (os pobres) aqueles que podem aceder ao estatuto de vítima. Os critérios são morais e humanistas, reiterando, de diversos modos, o estereótipo do "bom pobre", caracterizado pela honestidade, pelo trabalho e pela perseverança. É comum os entrevistados citarem como exemplo sua empregada doméstica.

0 outro "vítima" não faz parte da elite, mas é visto como igual a partir de uma visão humanista: "Eu tento quebrar essa barreira, eu não vejo a favela como um outro lugar, ou como um problema [...] São pessoas, são vidas, ali você tem pessoas interessantíssimas, tem corações formidáveis [...] 0 que vale é quem é a pessoa, como é 0 coração 
dessa pessoa (B)." Ou ainda: "Eu sei que tem muita gente que é boa e que mora lá (F)." Este outro é também aquele com quem 0 entrevistado teve contato. Todos os jovens dizem ter tido contatos cordiais e mesmo amizades com pessoas das classes desfavorecidas.

0 conhecimento pessoal permite aos

entrevistados colocarem-se no lugar do outro com mais facilidade. Essa é a ocasião em que os "bons pobres" são vistos como aqueles que mais sofrem com o crime. A partir dessa perspectiva, as operações da polícia nas favelas são chamadas de chacina. Mesmo nesse registro inclusivo, porém, aparecem aqui e ali os signos da ordem moral da Força, que constrói os pobres como classe perigosa. Se o registro inclusivo fosse o único a dominar, todos os pobres, com exceção dos criminosos, seriam incluídos no "nós" das vítimas. Contudo, no discurso dos entrevistados, essa ordem lógica é invertida: todos os pobres podem ser perigosos, embora conheçam alguns que são bons. A fronteira do "nós" é alargada, mas não a relação de base associando o grupo das vítimas às classes favorecidas.

Um outro índice da coexistência das duas ordens ocorre quando os jovens pensam a solução para 0 crime; as políticas sociais (como melhoria do ensino fundamental) são sempre associadas a políticas de "pulso firme". Embora a operação policial no Complexo do Alemão seja percebida como uma solução de curto prazo, que não resolve grandes coisas e causa o sofrimento de inocentes, mesmo assim é uma solução. 0 uso da força não é totalmente desqualificado, mesmo se atinge inocentes: "Se você quer resolver isso para hoje, tem que ser esse tipo de ação. Só que é horrível, você acaba afetando muitas pessoas inocentes, que não tem culpa nenhuma na história, mas isso é o preço a pagar. Mas é fácil de falar quando 0 preço não é comigo. Não vão invadir minha casa para matar os traficantes. Mas visto de fora, parece o preço a pagar (F)." Mais radicalmente, a ordem moral da Força está presente no discurso simplesmente porque a violência policial não é recusada, apenas a falta de critérios na sua aplicação. Para os "bandidos", a Força é legítima.

\section{Registro exclusivo}

No registro exclusivo, a tendência é restringir o grupo das vítimas à elite. Marcados por um forte sentimento de insegurança, os entrevistados recusam, de diferentes modos, o estatuto de vítima aos pobres, que tendem a ser caracterizados como "classe perigosa". Um primeiro modo de restrição é tratá-los como massa, utilizando a imagem das inúmeras favelas que teriam invadido a "Cidade Maravilhosa". 0 pronome "eles" é utilizado sem que se saiba precisamente a quem estão se referindo. Como os pobres são percebidos apenas no que têm de diferentes e não no que podem ter de semelhantes, aqui os jovens entrevistados não se esforçam para se colocar no lugar do outro, apenas temem: "Eu me sinto mal de estar no meio de pessoas tão diferentes de mim, sei 
lá, eu não sei como elas se sentem, sabe, se elas são conformadas com isso, com que elas nasceram numa classe pobre mesmo (C)." Essa representação dos pobres faz da diferença apenas um marcador de risco. Paralelamente, o que é identificado como causa da violência não é a segregação social, mas a proximidade espacial: "É uma segregação social que necessariamente te deixa muito inseguro, porque você esta convivendo ali cara a cara com uma classe social que está inferior a você. Então é um medo constante de uma coisa acontecer (C)."

A partir desse desconhecimento reconhecido e almejado, os jovens entrevistados recorrem a estereótipos para falar da vida urbana, fazendo dos pobres causadores de perturbação e caos. É surpreendente a semelhança das entrevistas com o discurso da elite paulista nas décadas de 80 e 90 sobre 0 crime analisado por Caldeira (2001). Aparece até a relação entre sujeira, desordem e violência como característica das favelas e dos pobres. Diz um entrevistado; "Assim (sem favela por perto), você se sente um pouco mais seguro. Não é que a favela me incomode necessariamente, mas dá uma sensação de segurança. Outra coisa também que me passa essa sensação de segurança é pouco mendigo na rua... Não que eles sejam sujos, mas, assim, dá uma sensação meio ruim, né. (F)"

Os entrevistados usam o termo "violência" não apenas para se referirem ao risco de assaltos ou de homicídios. Violência designa tudo o que simbolicamente agride o indivíduo: a circulação agressiva de vans ou motos ("o trânsito é uma consequiência da favelização (C)") ou os mendigos, que "pedem sem cessar" e tentam "se aproveitar de nós". Mas o pobre é, sobretudo, aquele que traz o risco do crime. Existe uma forte associação no discurso entre o pobre e 0 criminoso, mesmo quando o entrevistado sabe que a associação é um estereótipo: "É horrível desconfiar das pessoas. Eu procuro não mostrar que eu desconfio. Porque eu acho que é muito desagradável. Eles não estão fazendo mal nenhum, e a gente desconfia (F)."

Quando narrava um assalto, diante da questão "como era 0 agressor", o entrevistado, não sem rodeios, descreveu os criminosos: "Tinham a cara de 20 anos, claramente moradores de favela ou comunidade pobre, e, sei lá, tipo pele escura, mas não necessariamente negros, mas claramente pobres [...] Mas, com certeza moradores de favela da zona sul (C)." Se os fatos contradizem 0 "marcador de risco", eles têm o valor de exceção: "Tenho um amigo que foi assaltado e ficou impressionado pela aparência do menino que assaltou ele. Não tinha cara de assaltante [...] Bem vestido, com roupa... como se fosse um menino daqui da zona sul, da classe média. Podia ser um menino que estudasse comigo! (F)" Essa percepção, associando pobreza com o caos, a sujeira, o desconhecido e o crime, está articulada às soluções preconizadas pelos entrevistados para gerir a questão da "violência urbana". No 
registro exclusivo, 0 apoio às medidas de "pulso firme" predomina. Se a Força predomina sobre a Lei, a forma de justificar a operação do Complexo do Alemão difere: é a solução de primeira ordem. 0 objetivo é matar os bandidos (não o de julgar e prender) e a morte de inocentes é preço aceitável.

Mesmo nessa situação onde a ordem moral da Força impulsiona o discurso, a ordem da Lei não está totalmente ausente. De fato, diante da questão "o que você pode fazer em relação ao problema do crime", os entrevistados afirmavam que nada e que tudo cabia ao Estado. A divisão é, uma vez mais, contextual: o "pulso firme" seria temporário e, depois, haveria uma polícia sem corrupção e o respeito à lei. Essa impotência declarada de indivíduos e onipotência desejada do Estado é lugar tanto midiaticamente designado, quanto posição própria da política contemporânea: a vítima é inteiramente passiva e cabe ao Estado competente proteger seus cidadãos.

\section{$7 \mathrm{~A}$ vítima virtual e a rotina}

Pode parecer que a oscilação na extensão da comunidade de vítimas e a aceitação do crescente rigor penal e policial sustentado pela construção dos criminosos como quase monstros a ameaçar os cidadãos são próprias da sociedade brasileira, com suas altas taxas de crime, com sua imensa desigualdade social e grande homogeneidade do discurso midiático. Diversos livros e artigos mostram, porém, que 0 rigor penal e o privilégio político e existencial da vítima estão presentes em diversos países do mundo, mesmo naqueles em que as taxas de crime são relativamente baixas (sobre a África do Sul, COMAROFF; COMAROFF, 2006; sobre os Estados Unidos, GARLAND, 2001, e SIMON, 2007; sobre a Nova Zelândia, PRATT, 2005; sobre a Inglaterra, LIANOS, 2001; sobre a França, CASTEL, 2003). Diferentes governantes vêm a público afirmar que os direitos humanos não são universais, pois ou são para seres humanos e não para "ratos" (CHEVIGNY, 2003), ou o primeiro e mais importante entre todos os Direitos Humanos é o da vítima - uma frase de 2006 do presidente francês Sarkozy dita ao pai de uma criança morta por um pedófilo. Cabe notar que o crime suscitou a aprovação de uma lei que autoriza usar técnicas preditivas para impedir que um criminoso saia da prisão após cumprir sua pena. De modo mais genérico, a partir de algum crime particularmente sensível, no qual 0 criminoso tinha acabado de sair da prisão por indulto ou por liberdade condicional, a legislação penal de diferentes países passou a incluir algum procedimento de cálculo de riscos, de punição preditiva, com a pena sendo adequada não ao ato cometido pelo criminoso, mas ao que se presume cientificamente que ele pode vir a fazer. Também cabe notar como, em diferentes cidades globais, marcadores de raça, etnia e condição social estão presentes na estigmatização de bairros onde predominam negros, imigrantes e pobres.

Essa semelhança global nos obriga a pensar que as políticas vinculando medo e alteridade não são uma conseqüência única e direta da 
intensidade do sentimento de insegurança ou das taxas efetivas de crime. De início, a semelhança parece estar associada à mudança moral recente. As culturas ocidentais contemporâneas são marcadas pela generalização da exigência de autenticidade: cada um deve buscar 0 que 0 realiza como indivíduo (TAYLOR, 2007). Essa generalização implica a hegemonia do princípio do não-dano (no harm), formulado por Stuart Mill ainda no século XIX, que propõe como único limite à busca individual da felicidade 0 dano que se causa ao outro. Assim, não há, no nível imediato, nenhum consenso sobre a boa vida; ao contrário, o que esse princípio exige é a tolerância em relação às múltiplas formas de ser e de se obter prazer. A vítima de crime violento, por sua vez, torna-se 0 lugar de consenso moral mínimo, até pela clareza moral de seu sofrimento (BOUTELLIER, 1999). Essa mudança responde também pela valorização cada vez maior da vida privada e do consumo. Sob outro ponto de vista, essa transformação erige a rotina segura como lugar de justiça.

Uma segunda razão é 0 surgimento de uma nova relação entre indivíduo e Estado que pode ser conceituada como "direito ao risco". Numa cultura em que a administração do presente e 0 cuidado de si encontram-se sobredeterminados por conseqüências futuras, 0 risco se torna 0 paradigma a partir do qual são pensadas noções fundamentais da vida pública, tais como a de liberdade e responsabilidade. Ainda que não formalizado juridicamente, 0 crescente papel desempenhado pela noção de risco nos processos contemporâneos de subjetivação sinaliza para emergência dessa nova figura do direito, isto é, o direito não escrito, mas provavelmente já internalizado pelos indivíduos, de que "ninguém deveria ser obrigado a alterar seu estilo de vida por que outros o expõem a riscos". Sua contrapartida positiva é: "as pessoas podem expor-se aos riscos que voluntariamente estão dispostos a correr". Cabe ao Estado impedir que outros inescrupulosos, "sem coração", dispostos a tudo por nada, sem nenhum respeito pela vida, ameacem nossa rotina.

Nesse modo de pensar, a responsabilidade de cada indivíduo em relação aos outros e à coletividade reduz-se ora a pagar seus impostos, ora a considerar como suas decisões privadas de consumo podem afetar os outros. A responsabilidade prescinde da mediação da política como forma da ação coletiva. Peças publicitárias institucionais sobre segurança pública tornam essa ausência evidente: nos Estados Unidos, um consumidor de drogas em boates é alertado por um amigo de que seu dinheiro financiava a Al-Qaeda; no Brasil, a peça publicitária mostra que o uso de drogas pode ter como conseqüência a morte de um próximo.

Cabe indagar se esse estreitamento da política é capaz de propiciar políticas públicas que efetivamente transformem a segurança ou se só abre espaço para políticas de "pulso firme" que, circularmente, pela legitimação da violência 
dos agentes estatais de controle social, agravam a "violência urbana" e, assim, ampliam 0

sentimento de insegurança

\section{Referências Bibliográficas}

BOUTELLIER, Hans. Morality and crime: the

significance of criminal justice in post-modern culture. Boston: Kluwer Academic, 1999.

CALDEIRA, Tereza. City of walls: crime, segregation and citizenship in São Paulo. Los Angeles: University of California Press, 2001.

CASTEL, Robert. Linsecurité sociale. Paris: Seuil, 2003.

CAVALCANTI, Mariana. Of shacks, houses and

fortresses: an ethnography of favela consolidation in Rio de Janeiro. 2007. Tese (Doutorado em

Antropologia)- Universidade de Chicago, Chicago, 2007.

CHEVIGNY, Paul. The populism of fear: politics of crime in the Americas. Punishment \& society, n. 5, v. 1, p.77-96, 2003.

COMAROFF, Jean; COMAROFF, John. Figuring Crime: quantifacts and the production of the un/real. Public culture, n. 18, 2006.

GARLAND, David. The culture of control. Chicago: University of Chicago Press, 2001.

LIANOS, Michalis. Le nouveau contrôle social. Paris: L'Harmattan, 2001.

MICHAUD, Yves. Changements dans la violence: essai sur la bienveillance universelle et la peur. Paris: Odile Jacob, 2002.

MISSE, Michel. Crime e violência no Brasil contemporâneo. Rio de Janeiro: Lúmen Júris, 2006.

NUSSBAUM, Martha. Upheavals of thought.

Cambridge: Cambridge University Press, 2001.
PAIN, Rachel. Place, social relations, and the fear of crime: a review. Progress in Human Geography, n. 24, v. 3, p. 365-87, 2000.

PRATT, John. Penal populism in New Zealand.

Punishment \& society, n. 7, v. 3, p. 303-22, 2005.

REIS, Elisa. Perception of poverty and inequality among Brazilian elites. In: ; Mick M0ORE (orgs.). Elite perceptions of poverty and inequality. Nova Iorque: Zed, 2005, p. 26-56.

RONY, Gaelle. Comment peut-on être européen? Identités européennes et identifications dans les discours médiatiques turcs, belges et français: l'Europe à l'épreuve de la Turquie. 2006. Tese (Doutorado em Sociologia)- Université Catholique de Louvain, Louvain, Bélgica, 2006.

SILVA, Luiz Antonio Machado. Sociabilidade violenta: por uma interpretação da criminalidade contemporânea no Brasil Urbano. Sociedade e Estado, n. 19, v. 1, p. 53-84, 2004.

SIMON, Jonathan. Governing through crime. Oxford: Oxford University Press, 2007.

TAYLOR, Charles. A secular age. Harvard: Harvard University Press, 2007.

VAZ, Paulo; SÁ-CARVALHO, Carolina; POMBO, Mariana. A vítima virtual e sua alteridade: a imagem do criminoso no noticiário de crime. Revista

FAMECOS, n. 30, p. 71-80, 2006.

Risco e sofrimento evitável: a imagem da polícia no noticiário de crimes. E-Compós, n. 4, p. 1-22, 2005.

ZALUAR, Alba. Para não dizer que não falei de samba. In: SCHWARCZ, Lilia Moritz (org.). História da vida privada no Brasil 4. São Paulo: Companhia das Letras, 1998. 


\section{Urban experience and crime narratives}

\section{Experiencia urbana y narrativas de crimen}

Abstract

In this article, we propose that crime news constitute today a key element in shaping the experience of the city and of otherness. We argue that the media deploys the logics of fear and of compassion as means of fostering the audience's identification with the suffering of strangers. We then analyze how descriptions of the city voiced by young members of Rio de Janeiro's elite articulate insecurity, poverty and justice, thus generally restating the possibilities of identity building offered by crime news.

\section{Keywords}

City. Crime. Insecurity. Victim.

Identity. Otherness.

\section{Resumen}

En este artículo, proponemos que las noticias son, hoy, un elemento decisivo en la conformación de la experiencia de la ciudad y de la alteridad. Para sustentar teóricamente y empíricamente la propuesta, argumentamos, en primer lugar, que la retórica de los medios de comunicación usa las lógicas del miedo y de la compasión para favorecer la identificación de la audiencia con el sufrimiento de extraños. En la secuencia, analizamos el cómo la descripción de la ciudad por jóvenes de la élite carioca articula inseguridad, pobreza e injusticia, reiterando en sus grandes líneas las posibilidades de construcción de identidad ofrecidas por las noticias de crimen.

\section{Palabras clave}

Ciudad. Crimen. Inseguridad. Víctima.

Identidad. Alteridad. 


\section{Expediente}

A revista E-Compós é a publicação científica em formato eletrônico da Associação Nacional dos Programas de Pós-Graduação em Comunicação (Compós). Lançada em 2004, tem como principal finalidade difundir a produção acadêmica de pesquisadores da área de Comunicação, inseridos em instituições do Brasil e do exterior.
E-COMPÓS I www.e-compos.org.br I E-ISSN 1808-2599

Revista da Associação Nacional dos Programas de Pós-Graduação em Comunicação. Brasília, v.11, n.1, jan./abr. 2008.

A identificação das edições, a partir de 2008, passa a ser volume anual com três números.

\section{CONSELHO EDITORIAL}

\section{Afonso Albuquerque}

Universidade Federal Fluminense, Brasil

Alberto Carlos Augusto Klein

Universidade Estadual de Londrina, Brasi

Alex Fernando Teixeira Primo

Universidade Federal do Rio Grande do Sul, Brasi

Alfredo Vizeu

Universidade Federal de Pernambuco, Brasil

Ana Carolina Damboriarena Escosteguy

Pontifícia Universidade Católica do Rio Grande do Sul, Brasil

Ana Silvia Lopes Davi Médola

Universidade Estadual Paulista, Brasil

André Luiz Martins Lemos

Universidade Federal da Bahia, Brasil

Ângela Freire Prysthon

Universidade Federal de Pernambuco, Brasil

Antônio Fausto Neto

Universidade do Vale do Rio dos Sinos, Brasil

Antonio Carlos Hohlfeldt

Pontifícia Universidade Católica do Rio Grande do Sul, Brasil

Arlindo Ribeiro Machado

Universidade de São Paulo, Brasil

César Geraldo Guimarães

Universidade Federal de Minas Gerais, Brasi

Cristiane Freitas Gutfreind

Pontifícia Universidade Católica do Rio Grande do Sul, Brasil

Denilson Lopes

Universidade Federal do Rio de Janeiro, Brasil

Eduardo Peñuela Cañizal

Universidade Paulista, Brasil

Erick Felinto de Oliveira

Universidade do Estado do Rio de Janeiro, Brasil

Francisco Menezes Martins

Universidade Tuiuti do Paraná, Brasil

Gelson Santana

Universidade Anhembi/Morumbi, Brasil

Hector Ospina

Universidad de Manizales, Colômbia

leda Tucherman

Universidade Federal do Rio de Janeiro, Brasil

Itania Maria Mota Gomes

Universidade Federal da Bahia, Brasil

Janice Caiafa

Universidade Federal do Rio de Janeiro, Brasil

Jeder Silveira Janotti Junior

Universidade Federal da Bahia, Brasil
John DH Downing

University of Texas at Austin, Estados Unidos

José Luiz Aidar Prado

Pontifícia Universidade Católica de São Paulo, Brasil

José Luiz Warren Jardim Gomes Braga

Universidade do Vale do Rio dos Sinos, Brasi

Juremir Machado da Silva

Pontifícia Universidade Católica do Rio Grande do Sul, Brasil

Lorraine Leu

University of Bristol, Grã-Bretanha

Luiz Claudio Martino

Universidade de Brasília, Brasil

Maria Immacolata Vassallo de Lopes

Universidade de São Paulo, Brasil

Maria Lucia Santaella

Pontifícia Universidade Católica de São Paulo, Brasil

Mauro Pereira Porto

Tulane University, Estados Unidos

Muniz Sodre de Araujo Cabral

Universidade Federal do Rio de Janeiro, Brasil

Nilda Aparecida Jacks

Universidade Federal do Rio Grande do Sul, Brasil

Paulo Roberto Gibaldi Vaz

Universidade Federal do Rio de Janeiro, Brasil

Renato Cordeiro Gomes

Pontifícia Universidade Católica do Rio de Janeiro, Brasil

Ronaldo George Helal

Universidade do Estado do Rio de Janeiro, Brasil

Rosana de Lima Soares

Universidade de São Paulo, Brasil

Rossana Reguillo

Instituto Tecnológico y de Estudios Superiores do Occidente, México

Rousiley Celi Moreira Maia

Universidade Federal de Minas Gerais, Brasil

Sebastião Carlos de Morais Squirra

Universidade Metodista de São Paulo, Brasil

Simone Maria Andrade Pereira de Sá

Universidade Federal Fluminense, Brasil

Suzete Venturelli

Universidade de Brasília, Brasil

Valério Cruz Brittos

Universidade do Vale do Rio dos Sinos, Brasil

Veneza Mayora Ronsini

Universidade Federal de Santa Maria, Brasil

Vera Regina Veiga França

Universidade Federal de Minas Gerais, Brasil

\section{COMISSÃO EDITORIAL}

Ana Gruszynski I Universidade Federal do Rio Grande do Sul, Brasil João Freire Filho I Universidade Federal do Rio de Janeiro, Brasil Rose Melo Rocha I Escola Superior de Propaganda e Marketing, Brasil

\section{CONSULTORES AD HOC}

Bianca Freire-Medeiros I Fundação Getulio Vargas, Brasil Josimey Costa da Silva I Universidade Federal do Rio Grande do Norte, Brasil Maria Conceição Golobovante I Pontifícia Universidade Católica de São Paulo, Brasil Marlyvan Moraes de Alencar I Centro Universitário SENAC-SP, Brasil Miriam de Souza Rossini I Universidade Federal do Rio Grande do Sul, Brasil Paulo Ribeiro I Pontifícia Universidade Católica do Rio de Janeiro, Brasil Rita Alves de Oliveira I Centro Universitário SENAC, Brasil

REVISÃO DE TEXTO E TRADUÇÃO I Everton Cardoso ASSISTÊNCIA EDITORIAL E EDITORAÇÃO ELETRÔNICA I Raquel Castedo
COMPóS I www.compos.org.br

Associação Nacional dos Programas de Pós-Graduação em Comunicação

Presidente

Erick Felinto de Oliveira

Universidade do Estado do Rio de Janeiro, Brasil erickfelinto@uol.com.br

Vice-presidente

Ana Silvia Lopes Davi Médola

Universidade Estadual Paulista, Brasil

asilvia@faac.unesp.br

Secretária-Geral

Denize Correa Araújo

Universidade Tuiuti do Paraná, Brasil

denizearaujo@hotmail.com 